\title{
Plasmonic nanostructures for light trapping in thin-film solar cells
}

\author{
S. Morawiec ${ }^{1}$, M. J. Mendes ${ }^{2}$, F. Priolo ${ }^{3,4}$ and I. Crupi ${ }^{5}$ \\ ${ }^{1}$ Institute of Physics Nicolaus Copernicus University (NCU), ul. Grudziadzka 5/7, 87-100 Torun, Poland \\ ${ }^{2}$ i3N/CENIMAT, Department of Materials Science, Faculty of Science and Technology, Universidade NOVA de Lisboa \\ \& CEMOP/UNINOVA, Campus de Caparica, Caparica, Portugal \\ ${ }^{3}$ Department of Physics and Astronomy, University of Catania \& CNR-IMM, via Santa Sofia 64, \\ 95123 Catania, Italy \\ ${ }^{4}$ Scuola Superiore di Catania, Università di Catania, Via Valdisavoia 9, 95123 Catania, Italy \\ ${ }^{5}$ Department of Energy, Information engineering and Mathematical models, University of Palermo, \\ Viale delle Scienze, Building 9, 90128 Palermo, Italy
}

\begin{abstract}
The optical properties of localized surface plasmon resonances (LSPR) sustained by selfassembled silver nanoparticles are of great interest for enhancing light trapping in thin film photovoltaics. First, we report on a systematic investigation of the structural and the optical properties of silver nanostructures fabricated by a solid-state dewetting process on various substrates. Our study allows to identify fabrication conditions in which circular, uniformly spaced nanoparticles are obtainable. The optimized NPs are then integrated into plasmonic back reflector (PBR) structures. Second, we demonstrate a novel procedure, involving a combination of opto-electronic spectroscopic techniques, allowing for the quantification of useful and parasitic absorption in thin photovoltaic absorber deposited on top of the PBR. We achieve a significant broadband useful absorption enhancement of $90 \%$ for $0.9 \mu \mathrm{m}$ thick $\mu \mathrm{c}-\mathrm{Si}: \mathrm{H}$ film and demonstrate that optical losses due to plasmonic scattering are insignificant below $730 \mathrm{~nm}$. Finally, we present a successful implementation of a plasmonic light trapping scheme in a thin film a-Si:H solar cell. The quantum efficiency spectra of the devices show a pronounced broadband enhancement resulting in remarkably high short circuit current densities $\left(J_{s c}\right)$.
\end{abstract}

Keywords - Plasmonic-enhanced light trapping, Localized surface plasmon resonance, selfassembly, nanoparticles, photovoltaics, thin film solar cells, subwavelength nanostructures

\section{INTRODUCTION}

In recent years, the optimization of light trapping schemes in thin film solar cells has been intensively investigated and a number of promising approaches has been identified [1-5], among others, far field scattering from subwavelength metallic nanoparticles (NPs) sustaining localized surface plasmon resonances (LSPR) [6-8], which are reviewed in this paper. The pioneering work on the enhancement of light coupling into a semiconductor thin film, due to the resonant scattering from silver nanoparticles, was done in 1998 by Stuart and Hall [9], who demonstrated an enhancement in photocurrent of a silicon-on-insulator photodetector structure with dense nanoparticle arrays placed on top of the device. The application of plasmonic scattering for photovoltaics (PV) outbroke about ten years later with several demonstrations of photocurrent enhancements in silicon solar cells [10 12] supported by theoretical works [13-15].

The resonant interaction of light with the NPs at plasmonic resonance can result in both scattering and absorption of light. The beneficial effect of scattering consists in the extended path of the light inside the photovoltaic material, which increases the probability of scattered photons to be 
absorbed and generate photo-carriers. On the other hand, the parasitic absorption i.e. absorption occurring inside the NPs, can severely limit the overall photocurrent enhancement that can be produced in a solar cell due to light trapping [16-18]. Since the optical properties of plasmonic NPs depend strongly on their size, shape and local environment [19], the NPs for PV application should be properly designed and engineered in order to maximize the scattering and minimize the parasitic losses over the wavelength range important for light trapping.

The process commonly used for the fabrication of the NPs, known as solid-state dewetting (SSD), consists in thermally-induced transformation of morphology from a thin film into an array of droplets or nanoparticles [20,21]. Silver is the usual material of choice among the materials commonly used in plasmonics, due to its high radiative efficiency and low imaginary permittivity in the visible and near-infrared (NIR) spectrum [22,23].

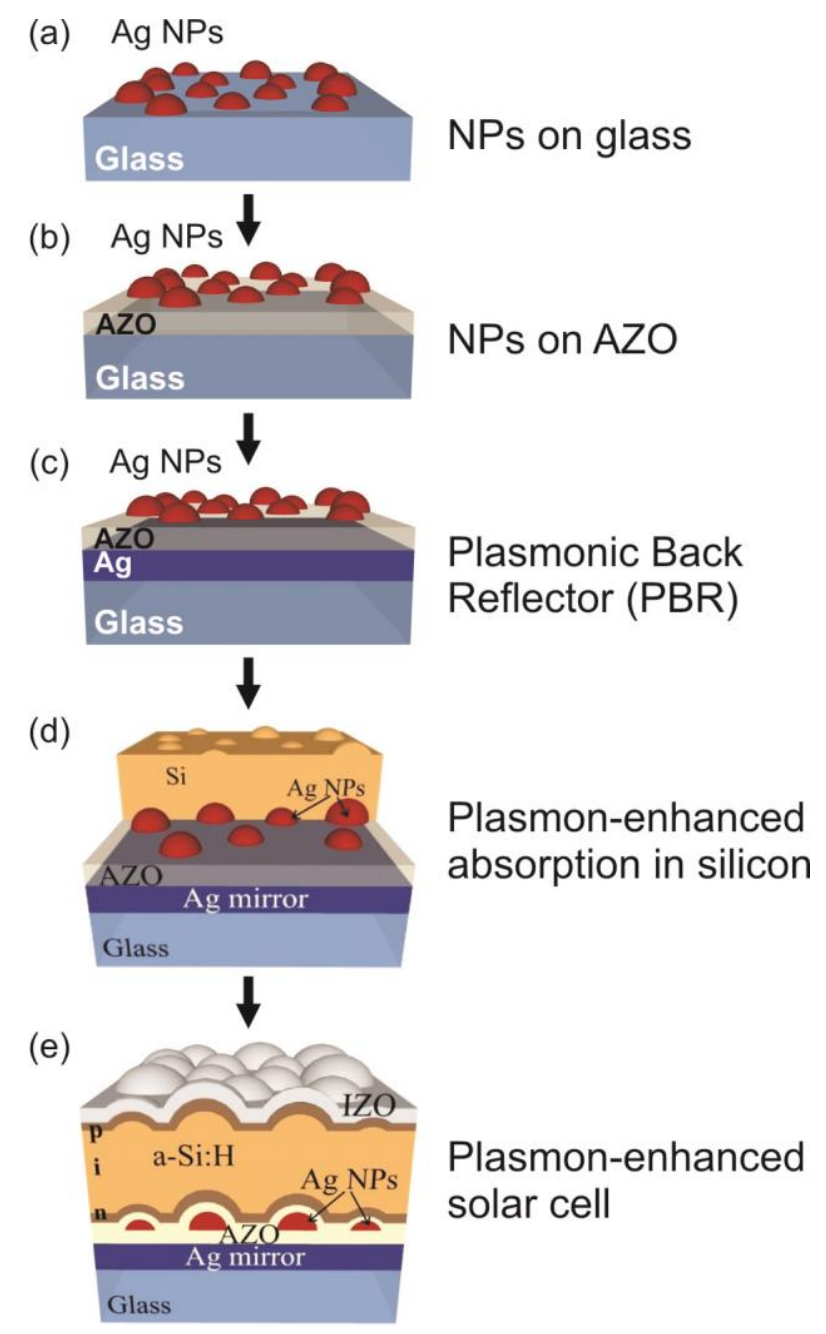

Fig. 1. Schema of the workflow for systematic investigation of NPs fabricated in distinct arrangements and their integration in $n-i-p$ thin film Si solar cells, presented in this paper.

Initial designs depended on NPs placed on the front surface of the solar cell. Further studies showed that it is more advantageous to incorporate the NPs in the rear side of the cell i.e. in proximity to the rear mirror. In such configuration, known as plasmonic back reflector (PBR), NPs 
interact only with light which was not absorbed during the first pass through the cell material [24,25] thus decreasing the parasitic loses. A standard configuration PBR consists of a flat silver mirror, a thin aluminum doped zinc oxide (AZO) spacer layer and the NPs deposited on the top. Thereafter, such stack can serve as a substrate for the deposition of any thin-film photovoltaic absorber [26,27]. It has been demonstrated that self-assembled NPs in a PBR configuration can provide light trapping performance comparable to state of the art random textures in thin film Si solar cells [28,29].

The workflow reported in this paper is schematically shown in Fig. 1. First, we present a systematic study of the structural and optical properties of self-assembled silver nanostructures, according to the fabrication parameters of the SSD process, on three consecutive stages of integration: (1) NPs fabricated on glass substrates - Fig. 1(a); (2) NPs embedded in aluminum doped zinc oxide (AZO) - Fig. 1(b); and (3) NPs assembled in a PBR structure - Fig. 1(c). Our study allowed us to identify fabrication conditions in which circular, uniformly spaced nanoparticles are obtainable. Second, we report on a novel method consisting in a combination of photothermal deflection spectroscopy (PDS) and Fourier-transform photocurrent spectroscopy (FTPS) developed to independently quantify the useful (generating photocurrent) and parasitic absorption of light in 0.9 $\mu \mathrm{m}$ thick $\mu \mathrm{c}-\mathrm{Si}: \mathrm{H}$ deposited on PBR substrates. Using this technique we demonstrate that the optical losses in the NPs are insignificant in the $400-730 \mathrm{~nm}$ wavelength range, beyond which they increase rapidly with increasing illumination wavelength. Furthermore, we achieve a significant broadband useful absorption enhancement of $90 \%$ relative to the flat $\mu \mathrm{c}-\mathrm{Si}: \mathrm{H}$ reference film. Last, we demonstrate successful implementation of plasmonic light trapping in a thin film a-Si:H solar cells fabricated on optimized PBR structures. The quantum efficiency spectra of the devices revealed a pronounced broadband enhancement, relative to the flat reference device without particles, which is attributed not only to the plasmon-assisted light scattering from the NPs but also to the front surface texture originated from the conformal growth of the cell material over the NPs. As a result, remarkably high values of open-circuit voltage $\left(V_{o c}\right)$ and short-circuit current density $\left(J_{s c}\right)$ are achieved in comparison to those previously reported in the literature for the same type of devices.

\section{EXPERIMENTAL DETAILS}

Self-assembled nanoparticles were fabricated by SSD of thin silver film of variable thicknesses, deposited using magnetron sputtering. Notably, the process is fully compatible with the industrial manufacturing lines of thin film solar cells. The thicknesses were measured by Rutherford backscattering spectrometry (RBS, $2.0 \mathrm{MeV} \mathrm{He}^{+}$beam) in high resolution mode. The post-deposition annealing process was performed in $\mathrm{N}_{2}$ atmosphere at a temperature ranging from 200 to $500{ }^{\circ} \mathrm{C}$ and time from 0.5 to $4 \mathrm{~h}$. The surface morphologies were characterized by Field Emission Scanning Electron Microscopy (SEM - Zeiss Supra 25 microscope) and Atomic Force Microscopy (AFM Bruker Dimension Icon microscope in PeakForce mode). The optical properties were measured with a Varian Cary 500 double-beam scanning UV-Vis-NIR spectrophotometer equipped with a 4-inch integrating sphere.

For the samples presented in section 3.2, a $0.9 \mu \mathrm{m}$ thick $\mu \mathrm{c}-\mathrm{Si}: \mathrm{H}$ layer was deposited on top of selected NP structures by Plasma Enhanced Chemical Vapor Deposition (PECVD). The absorption of light in the whole structures was measured by highly sensitive photothermal deflection spectroscopy (PDS), using a FluorinertTM Electronic Liquid FC-72 with low refraction index of 
1.25 to simulate conditions similar to air ambient. The useful absorption within the photovoltaic Si material was measured by Fourier-transform photocurrent spectroscopy (FTPS), using an arrangement with coplanar front electrode made of electrolyte and a transparent conductive oxide sandwich structure.

The n-i-p a-Si:H solar cells presented in section 3.3 were deposited on optimized PBRs at $170^{\circ} \mathrm{C}$ using a multi-chamber PECVD system. The n-i-p structure consists of $33 \mathrm{~nm}$ n-type amorphous, $300 \mathrm{~nm}$ intrinsic amorphous, $13 \mathrm{~nm}$ p-type nanocrystalline and $7 \mathrm{~nm}$ p-type amorphous $\mathrm{Si}: \mathrm{H}$. Deposition of silicon is followed by the sputter deposition of a $240 \mathrm{~nm}$ thick indium doped zinc oxide (IZO) front contact. To improve the electrical performance, all the cells are annealed in low vacuum at $150{ }^{\circ} \mathrm{C}$ for $2 \mathrm{~h}$. The solar cells are characterized by measuring the $\mathrm{J}-\mathrm{V}$ curves under AM1.5G illumination (Spire Sun Simulator 240A), and the external quantum efficiency (EQE) in short-circuit condition in the 350-800 nm wavelength range. The $V_{o c}$ and fill factor (FF) of the cells are extracted from the $\mathrm{J}-\mathrm{V}$ curves while the $J_{s c}$ is determined from the integration of the EQE multiplied by the AM1.5G photon flux.

\section{RESUltS AND DiSCUSSION}

\section{1. $\quad$ Self-assembled Ag nanoparticles}

Solid-state dewetting is a process of morphology transformation from a thin film to an array of nanoparticles induced by thermal annealing. The phenomenon is driven by the minimization of the surface free energy of the film, the substrate and the film-substrate interface. The threshold temperatures for dewetting are well below the melting point of the material, since as-deposited thin films are in general metastable, and the surface diffusion driven mass transport is proportional to the temperature.

The SSD process produces particle ensembles with broad distribution of size. Therefore, analysis of morphology and correlation with optical properties requires statistical approaches commonly realized by histograms of NP sizes. However, the mean size of the NP is not a good parameter to describe the optical properties of ensembles with broad size distribution, because the absorption and scattering cross-sections of single NPs depend strongly on the NP size. Thus, we propose to calculate histograms of surface coverage as a sum of NPs' areas with size (longitudinal diameter) with a certain range, dived by the total investigated sample area. Such histograms reveal NP size that cover the greatest area and thus have the highest impact on the optical properties of the entire ensemble. 

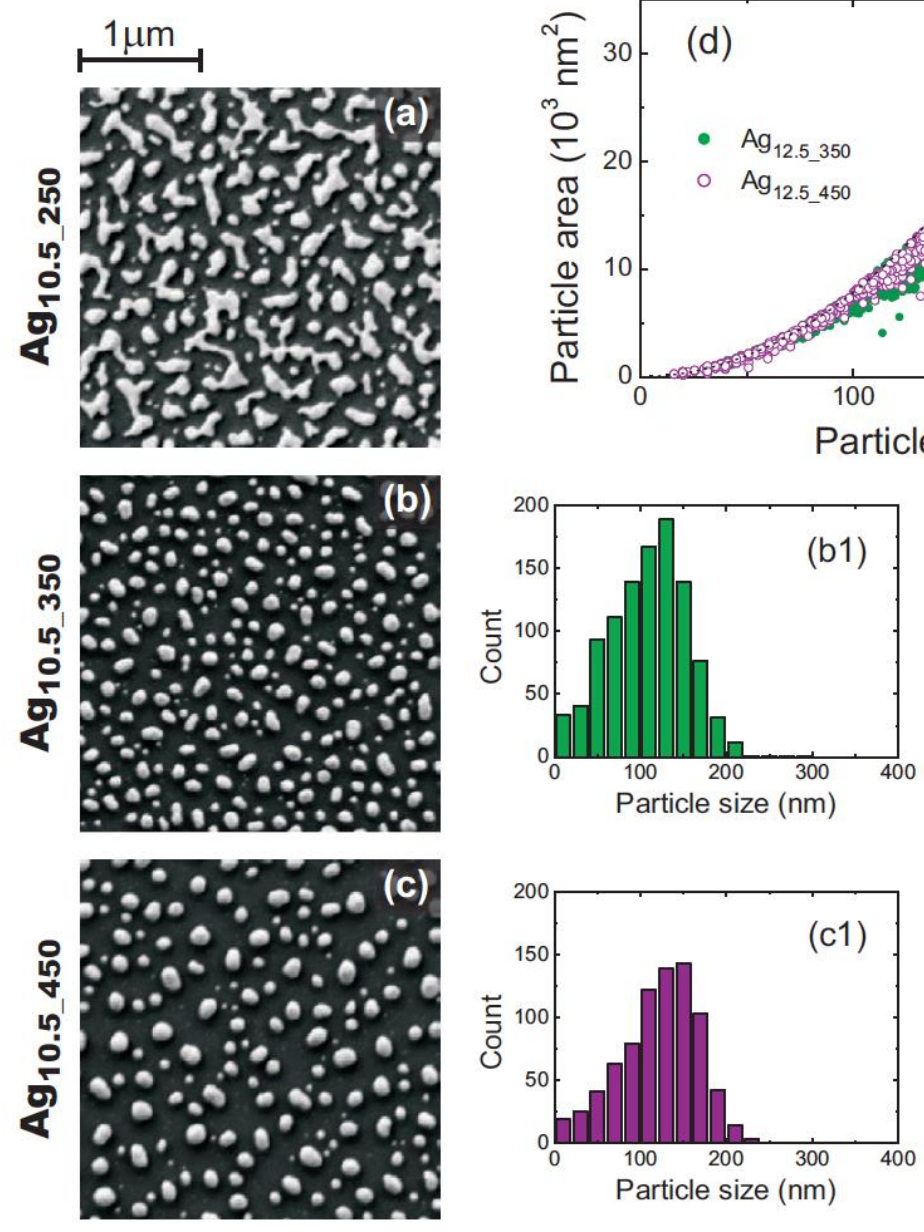
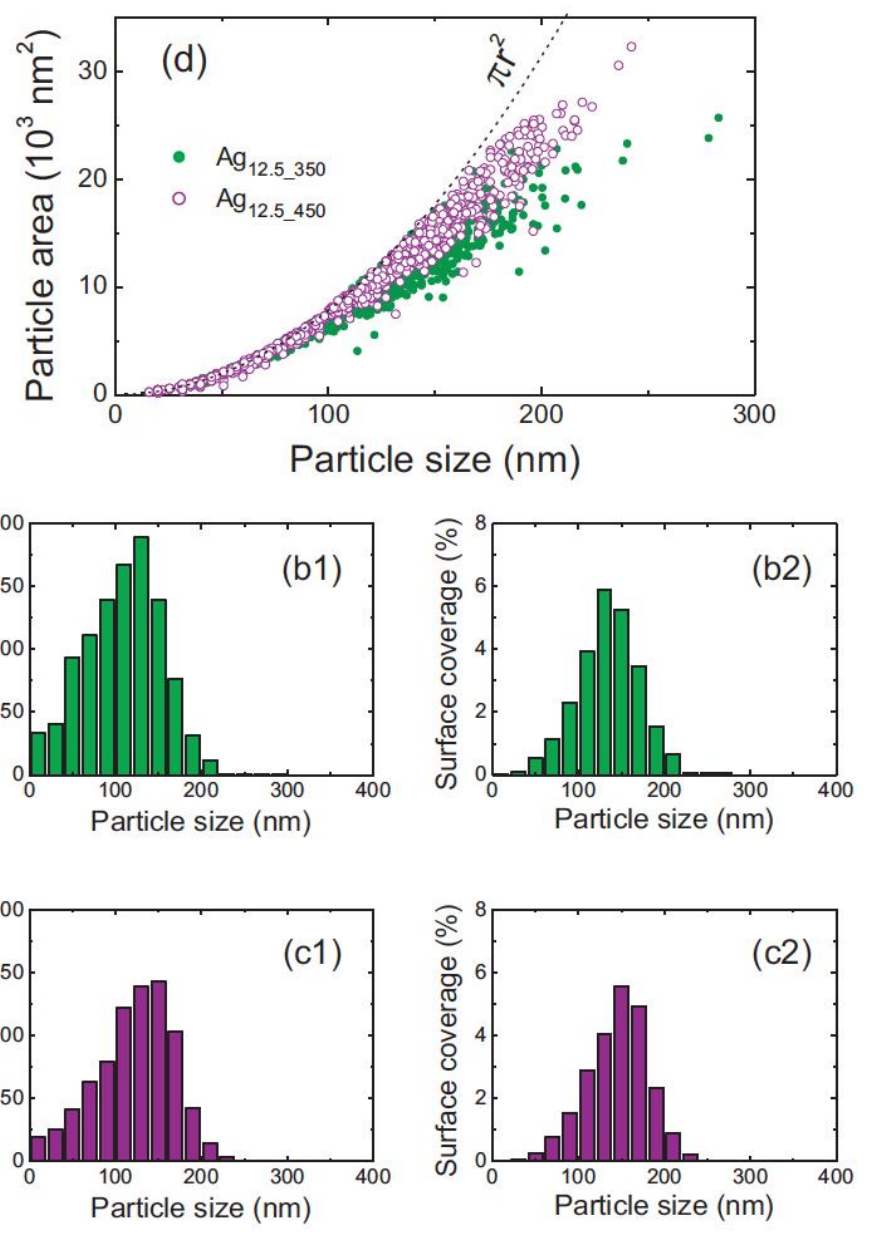

Fig. 2: SEM images of Ag NPs formed after annealing of $10.5 \mathrm{~nm}$ thick precursor films for $1 \mathrm{~h}$ at (a) $250^{\circ} \mathrm{C}$, (b) $350^{\circ} \mathrm{C}$ and (c) $450^{\circ} \mathrm{C}$. The histograms of NPs' size (longitudinal diameter) and surface coverage of sample $\mathrm{Ag}_{10.5 \_350}$ are shown in (b1) and (b2), and for sample $\mathrm{Ag}_{10.5 \_450}$ in (c1) and (c2), respectively. The plot of particle area vs. particle size is shown in (d).

Figure 2 depicts the morphology of NPs fabricated by SSD on glass substrates (schematically shown in Fig. 1(a)) and corresponding statistical analysis. SEM images of NPs formed from $10.5 \mathrm{~nm}$ thick $\mathrm{Ag}$ precursor films annealed for $1 \mathrm{~h}$ under three different temperatures of $250^{\circ} \mathrm{C}, 350^{\circ} \mathrm{C}$ and $450^{\circ} \mathrm{C}$ (sample $\mathrm{Ag}_{10.5 \_250}, \mathrm{Ag}_{10.5 \_350}$ and $\mathrm{Ag}_{10.5 \_450}$, respectively) are shown in figs. 2(a-c). The size (longitudinal diameter) and surface coverage histograms for samples $\mathrm{Ag}_{10.5 \_350}$ are shown in figs. 2(b1) and 2(b2) and for sample $\mathrm{Ag}_{10.5} 450$ in figs. 2(c1) and 2(c2), respectively. In the low annealing temperature regime, the formation of irregular nanoclusters was observed and, due to uncertainties in definition of particle size, histograms are not available. Well defined and ellipsoidal NPs were obtained above $350^{\circ} \mathrm{C}$. With a further increase of the annealing temperature, up to $450^{\circ} \mathrm{C}$, an aggregation process of NPs initiates, the size uniformity of the NPs increases and the number of small particles decreases. Furthermore, the mean surface coverage (SC) size of NPs, determined by the maximum of Gaussian single-peak fitting to the surface coverage histograms, increases from $136 \pm 0.8$ up to $149 \pm 0.5 \mathrm{~nm}$, with almost unchanged full width at half maximum of $78.5 \mathrm{~nm}$. The total $\mathrm{SC}$ decreases from $25.1 \%$ for $\mathrm{Ag}_{10.5 \_350}$ to $23.5 \%$ for $\mathrm{Ag}_{10.5 \_450}$. Therefore, since there is no significant loss of Ag during the annealing, the mean height of the NPs is expected to increase with 
the annealing temperature. The shape uniformity in terms of in-plane roundness of the particles increases with annealing temperature, as shown in the plot of particle area against particle size (longitudinal diameter), Fig. 2(d), where the perfectly round particles should lie along the dashed $\pi r^{2}$ curve. The NPs smaller than $100 \mathrm{~nm}$ are approximately round for both $\mathrm{Ag}_{10.5 \_350}$ and $\mathrm{Ag}_{10.5} \_450$, whereas bigger particles tend to be elongated. Nonetheless, the roundness of NPs is notably increased for annealing temperatures of $450^{\circ} \mathrm{C}$ [21].

Considering Mie theory, the absorption cross section of a spherical NP with diameter $a$ scales with particle volume $\left(\propto a^{3}\right)$, while the cross-section for scattering scales with volume squared $\left(\propto a^{6}\right)$. Thus, the optical response of small NPs $(a<10 \mathrm{~nm})$ is dominated by absorption. The scattering efficiency (ratio between scattering and absorption cross-section) increases rapidly with NP size and saturates for NPs with $a>100 \mathrm{~nm}$. Therefore, the optical response of such "big" particles is dominated by scattering [30].

The optical properties of the samples presented in Fig 2, in terms of their absorption $(A b s)$, total reflection $\left(R_{\text {Total }}\right)$ and diffused parts of transmission $\left(T_{\text {Diff }}\right)$ and reflection $\left(R_{\text {Diff }}\right)$ are depicted in Fig. 3. The plots present the properties of the NPs only (though in the presence of substrate) as the background effects of the glass substrate, in terms of its reflection and absorption, were subtracted from the raw optical measurements. The irregular nanostructures of $\mathrm{Ag}_{10.5} 250$ exhibit wide spectral response as expected from the wide spread of NPs' sizes and shapes. This kind of structure also exhibits highest parasitic absorption. As the NPs become rounder, due to the elevated annealing temperature, the LSPR spectra become narrower and the absorption is notably reduced.

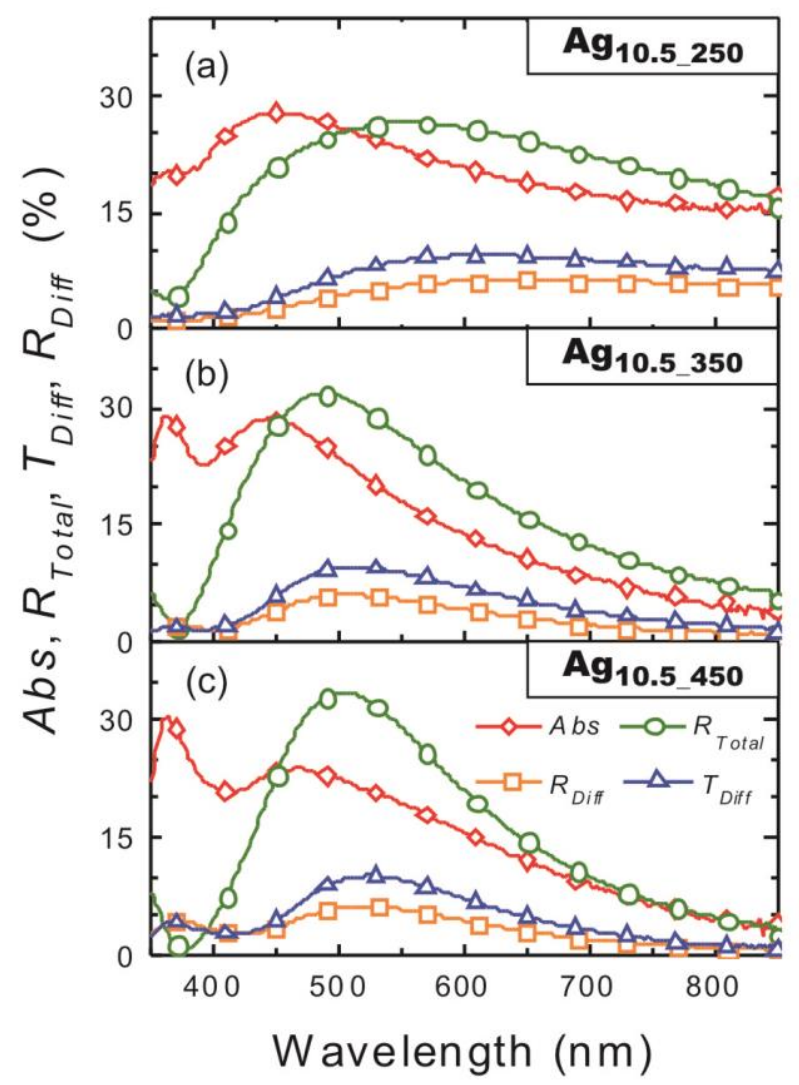


Fig. 3. Absorption $(A b s)$, total reflection $\left(R_{\text {Total }}\right)$ and diffused parts of transmission $\left(T_{D i f f}\right)$ and reflection $\left(R_{D i f f}\right)$ of $10.5 \mathrm{~nm}$ thick Ag precursor film annealed in the range of temperatures between $250^{\circ} \mathrm{C}$ and $450^{\circ} \mathrm{C}$

For well-defined circular NPs, obtainable at elevated temperatures, the mean SC size was found to increase linearly with the thickness of the precursor film in the range of 6 to $23 \mathrm{~nm}$ (see ref [21]). In agreement with theoretical predictions, the LSPR wavelength was found to redshift with increasing size of the NPs. Fig. 4 depicts the dependence of the LSPR wavelength on the mean SC size obtained for circular NPs fabricated at different temperatures. This demonstrates that the resonance of our self-assembled NPs is spectrally tunable within the $420-580 \mathrm{~nm}$ range at a $1.05 \pm$ $0.07 \mathrm{~nm} / \mathrm{nm}$ rate, as determined from the linear regression fit to the points corresponding to temperatures above $300^{\circ} \mathrm{C}$. With an increasing mean SC size a significant broadening of LSPR spectra was also observed. The mean SC size is a meaningful statistical parameter to describe the distribution of particles within the nanostructure, indicating what size within the distribution plays the major role in determining the optical properties of the entire assembly.

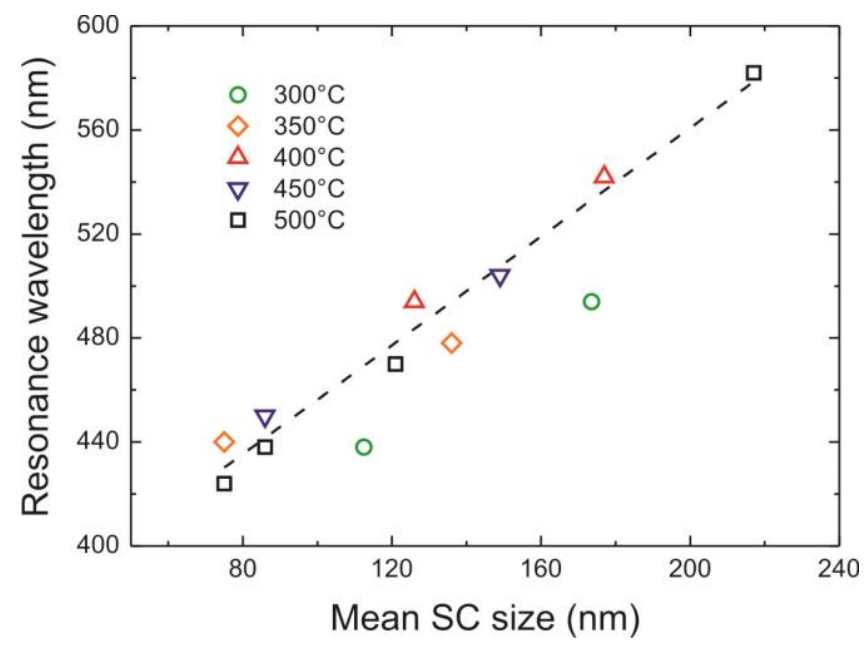

Fig. 4. Dependence of the resonance wavelength (spectral position of the localized surface plasmon resonance extinction peak) on the mean surface coverage (SC) size. The dashed line shows the linear regression fit (slope $1.05 \pm 0.07 \mathrm{~nm} / \mathrm{nm}$ ) for temperatures higher than $300^{\circ} \mathrm{C}$. 

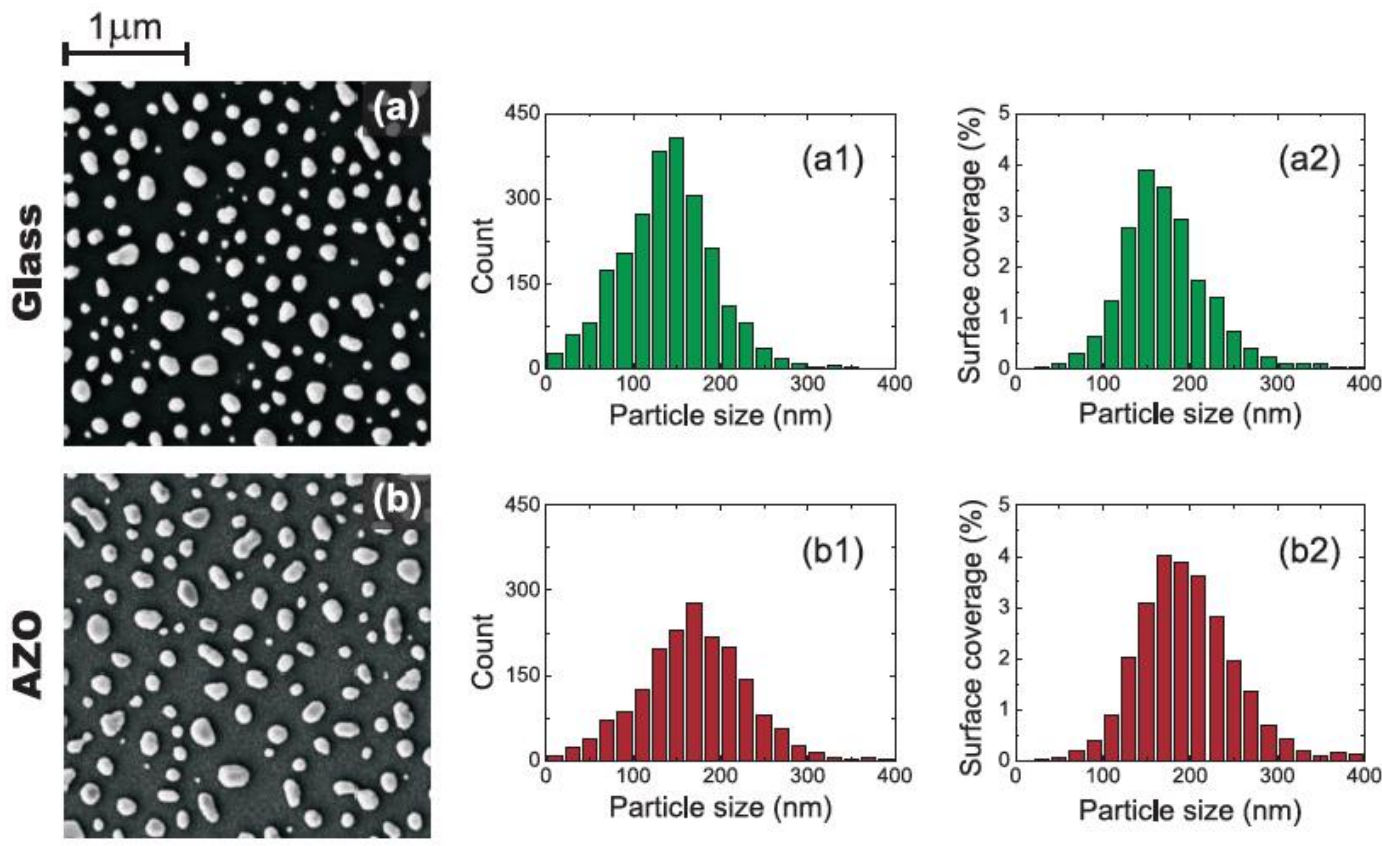

Fig. 5: SEM images of Ag NPs formed on (a) bare glass and (b) glass coated with $50 \mathrm{~nm}$ of AZO after annealing of $12 \mathrm{~nm}$ thick precursor films for $1 \mathrm{~h}$ at $400^{\circ} \mathrm{C}$. The corresponding histograms of NPs' sizes (in-plane diameter) are shown in (a1) and (b1), while the surface coverage histograms are shown in (a2) and (b2).

For application in thin film silicon solar cells, the NPs are embedded in the AZO layer and located at the rear side of the device, so that they interact only with the photons that are not absorbed during the first pass through the cell absorber material. Therefore, in the succeeding experiment we investigated the properties of self-assembled Ag NPs formed on- and embedded in AZO films. Figure 5 compares the morphology and presents statistical analysis of NPs fabricated in the exact same process, on (a) bare glass, and (b) glass coated with $50 \mathrm{~nm}$ of AZO, after annealing of $12 \mathrm{~nm}$ thick Ag precursor films for $1 \mathrm{~h}$ at $400^{\circ} \mathrm{C}$. Nanoparticles formed on AZO tend to be larger than those formed on glass [31], though the maximum sizes of NPs are approximately the same in both cases. The average NPs' size and the mean SC size increase from $139 \pm 2 \mathrm{~nm}$ to $169 \pm 2 \mathrm{~nm}$ and from $164 \pm 2$ $\mathrm{nm}$ to $190 \pm 1 \mathrm{~nm}$, respectively. Furthermore, the relative number of small particles as well as the overall number of particles is reduced on AZO. In addition, the total surface coverage increases from $20.3 \%$ to $26.1 \%$, which reveals that NPs formed on AZO also tend to be more flat than those formed on glass substrate. All the morphological differences described above can be attributed to the higher surface free energy of AZO than glass. 


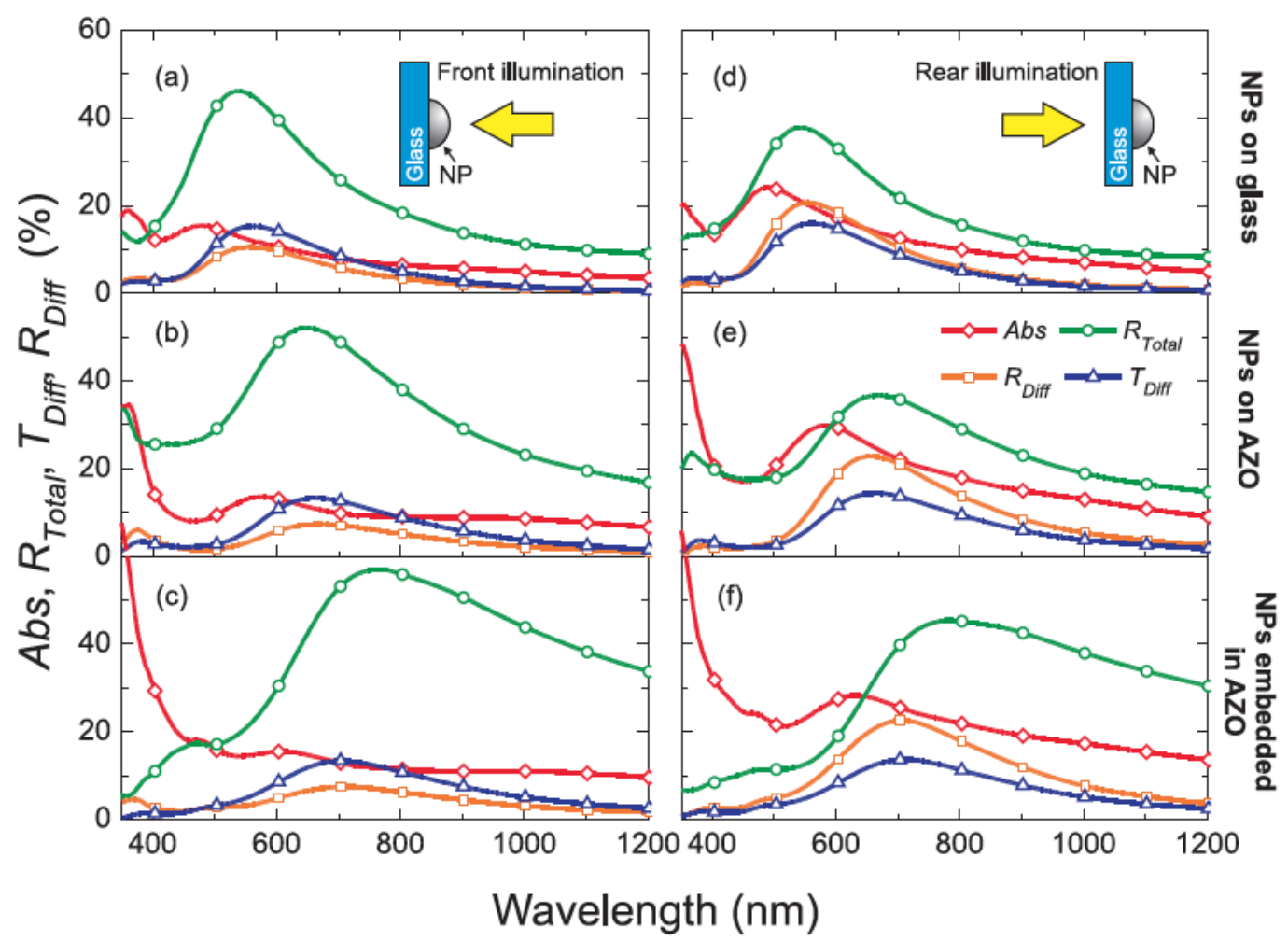

Fig. 6: Abs, $R_{\text {Total }}, T_{\text {Diff }}$ and $R_{\text {Diff }}$ of NPs formed from $12 \mathrm{~nm}$ thick $\mathrm{Ag}$ films annealed at $400^{\circ} \mathrm{C}$ for $1 \mathrm{~h}$ in three different configurations: NPs on glass (a) and (d), NPs on $50 \mathrm{~nm}$ thick AZO (b) and (e), and NPs embedded in $100 \mathrm{~nm}$ thick AZO (d) and (f). Left column corresponds to the frontand right column to the rear-side illumination.

The deposition of the NPs on AZO instead of glass influences also their optical response, due to the higher effective refractive index of the medium surrounding the NPs. Figure 6 depicts the comparison between the $A b s, R_{\text {Total }}$ and $T_{\text {Diff }}$ and $R_{\text {Diff }}$ spectra of particles analyzed in Fig. 5 formed in the same process on bare glass (Fig. 6(a) and 6(d)), on glass coated with $50 \mathrm{~nm}$ thick AZO (Fig. 6(b) and 6(e)), and NPs formed on $50 \mathrm{~nm}$ thick AZO and over-coated with another $50 \mathrm{~nm}$ thick AZO layer (labeled as NPs embedded in AZO, Fig. 6(c) and 6(e)). The contribution of substrates has not been subtracted from the measurements, thus the absorption edges of glass and AZO are clearly observed at $350 \mathrm{~nm}$ and $400 \mathrm{~nm}$, respectively. The deposition of NPs on AZO and subsequent overcoating with AZO causes an increase of the effective refractive index of the material surrounding the NPs. This results in (a) pronounced spectral broadening of the resonance spectra; (b) significant redshift of the plasmonic resonance from $555 \mathrm{~nm}$ for NPs on glass, to $640 \mathrm{~nm}$ for NPs on AZO, and to $730 \mathrm{~nm}$ for NPs embedded in AZO (by the means of total light extinction).

Significant differences in the optical properties of the NPs were observed for measurements performed in two distinct configurations: front-side illumination (left-hand column in Fig. 6), when the incident light impinges the NPs first, and rear side illumination (right-hand column in Fig. 6), when the incident light impinges the glass substrate first. These two configurations correspond to the way in which NPs interact with the sunlight in substrate and superstrate thin film solar cell structures, respectively. Interestingly, the extinction spectra (sum of all interactions between incident light and the NPs) were found not to depend on illumination configuration. For the rear side illumination we measured a lower $R_{\text {Total }}$, which for constant extinction leads to a notably higher absorption. However, $R_{\text {Diff }}$ is almost doubled in this configuration while its spectral shape is only 
moderately narrower. The asymmetry between the two illumination configurations should be attributed to the asymmetry of the refractive index around the NPs as well as to their hemispherical cross-section shape. The higher absorption in the rear-side illumination can also explained by the significantly higher coupling of light into a planar waveguide formed by the AZO layer. This stays in good agreement with the results of Pennanen and Toppari [32] that for $\mathrm{TiO}_{2}$ waveguide and gold nanodisks the forward scattering is approximately equal regardless the illumination direction while the backscattering is much stronger towards the high refractive index material resulting in much higher coupling efficiency.

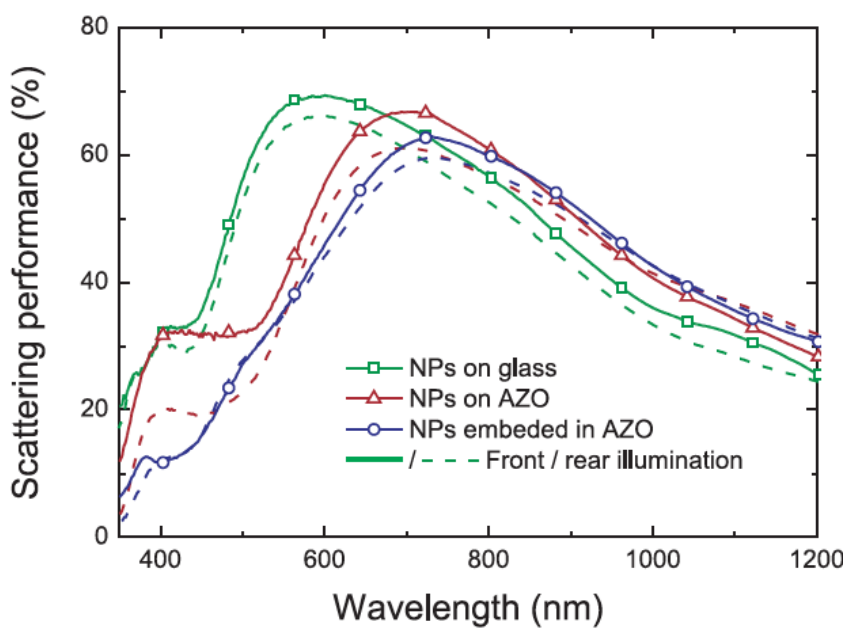

Fig. 7: Spectra of the scattering performance $\left(\gamma_{\text {scatt }}\right)$ of Ag NPs formed from $12 \mathrm{~nm}$ thick Ag films annealed at $400^{\circ} \mathrm{C}$ for $1 \mathrm{~h}$ in three different configurations: NPs on glass, NPs on $50 \mathrm{~nm}$ thick AZO, and NPs embedded in $100 \mathrm{~nm}$ thick AZO. Solid lines correspond to front- and dashed to rear-side illumination.

For application in solar cells, there is a clear trade-off between the beneficial effects of light scattering and the adverse parasitic absorption limiting the achievable enhancements. Therefore, we evaluated the scattering performance, $\gamma_{\text {scatt }}$, of our nanostructures as:

$$
\gamma_{s c a t t}=\frac{T_{\text {diff }}+R_{\text {diff }}}{A b s+T_{\text {diff }}+R_{\text {diff }}}
$$

Figure 7 shows the spectra of $\gamma_{\text {scatt }}$ for the three samples characterized in Fig. 6, for both front and rear illumination conditions. Due to the higher parasitic absorption for the NPs deposited on AZO, the maximum $\gamma_{\text {scatt }}$ values are moderately reduced in comparison with NPs on bare glass. This is partially caused by the small absorption occurring in the AZO layer, which was not subtracted from the measurements. Additionally, $\gamma_{\text {scatt }}$ shows lower values for rear-side illumination compared to the front-side illumination (depicted in Fig. 7 by dashed and solid lines, respectively) for the three sample configurations. The values of both scattering and absorption are higher for rear-side illumination (Fig. 6), however, more pronounced parasitic absorption surpasses the beneficial effect of higher scattering observed in the rear side illumination. 

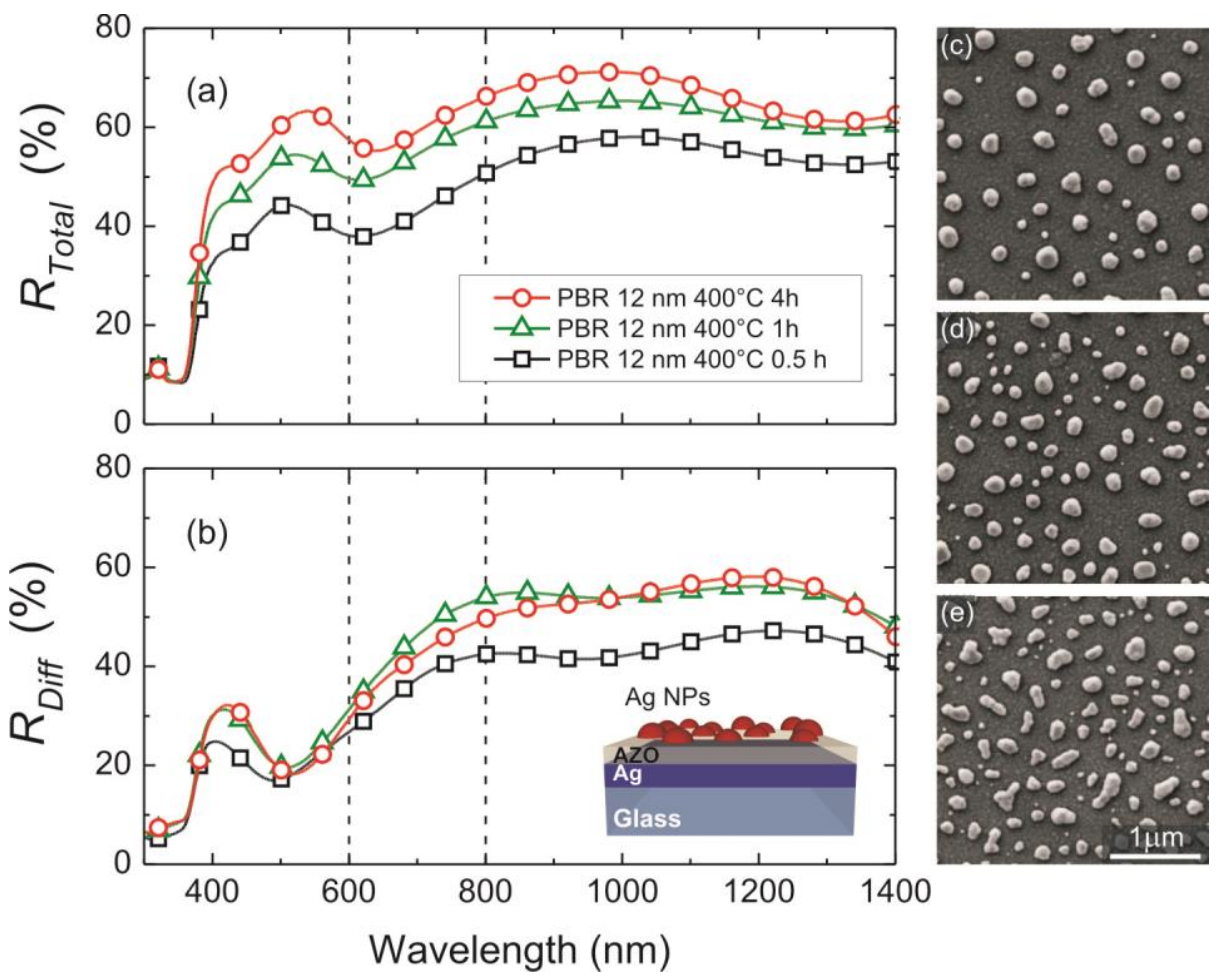

Fig. 8. (a) Total and (b) diffuse reflection of the PBRs with NPs formed from $12 \mathrm{~nm}$ thick $\mathrm{Ag}$ films annealed at $400^{\circ} \mathrm{C}$ for $0.5,1$, and $4 \mathrm{~h}$. The corresponding NPs' morphology is shown in the SEM images (c), (d), and (e), respectively. The preferential light trapping wavelength range of a$\mathrm{Si}: \mathrm{H}(600-800 \mathrm{~nm})$ solar cells is indicated by the vertical dashed lines.

In the following experiment we investigated the NPs' morphology incorporated in PBR (schematically shown in Fig. 1(c)) and corresponding optical properties of a complete structures. PBRs are fabricated by sequential deposition of $100 \mathrm{~nm}$ thick silver mirror, $40 \mathrm{~nm}$ thick AZO spacer layer and Ag precursor film. In the annealing process topmost thin layer of Ag forms the NPs. In the last stage NPs were coated with $80 \mathrm{~nm}$ thick AZO layer. Figure 8 depicts the annealing time dependent evolution of the NPs' morphology formed in PBR configuration from $12 \mathrm{~nm}$ thick Ag films at $400^{\circ} \mathrm{C}$ for $0.5,1$, and $4 \mathrm{~h}$, and the corresponding changes of the PBR optical response. The SEM micrographs in Fig. 8 show NPs without last coating layer. The extended annealing time clearly favors the formation of more uniform sizes and shapes of NPs. Furthermore, the surface coverage and the number of small particles decreases, leading to a structure practically without NPs smaller than $80 \mathrm{~nm}$ obtained by annealing with prolonged time $(4 \mathrm{~h})$. The changes in NPs' morphology result in the improvement of their optical performance, namely reduced parasitic absorption seen as the increase of $\mathrm{R}_{\text {Total }}$ over the entire investigated spectral range. The slight reduction of $R_{\text {Diff }}$ in the 600 - $800 \mathrm{~nm}$ range between 1 and $4 \mathrm{~h}$ can be attributed to a slightly lower number of particles with sizes around $100 \mathrm{~nm}$. The most pronounced improvements of both total and diffuse reflections were observed with annealing time increased from 0.5 to $1 \mathrm{~h}$, which results from the fact that the rate of morphological changes saturates, approaching the thermal equilibrium condition.

The ratio of $R_{\text {Diff }}$ to $R_{\text {Total }}$ for a PBR containing NPs annealed for $1 \mathrm{~h}$ approaches $90 \%$ in the $700-1300 \mathrm{~nm}$ wavelength range. Such haze in reflection indicates that vast majority of the incident photons interact with the NPs, since almost all the light that is not absorbed is reflected diffusively 
from the PBRs. Therefore, the main factor limiting the performance of the PBRs is the parasitic absorption. In this respect, there is a significant discrepancy between theoretical calculations and experimental results. According to single-particle electromagnetic modeling, Ag NPs with sizes above $100 \mathrm{~nm}$ should exhibit dominant scattering and negligible absorption cross sections $[6,13,15,30]$. Although the origin of the unexpectedly high absorption remains unclear, it can be attributed to: (1) presence of small NPs; (2) roughness and sharp features of the NPs acting as hotspots; (3) dissipative interactions between the NPs and between the NPs and the mirror [33]; and (4) impurities, defects and polycrystalline nature of the material forming the NPs [34].

\subsection{Absorption enhancement in thin $\mu c$-silicon films}

In order to investigate the light trapping effects in substrate configuration thin film solar cells, selfassembled silver nanoparticles were incorporated in three distinct arrangements, considered as different stages of completion of a plasmonic back reflector (shown in Fig. 9), subsequently used as substrates for the deposition of $0.9 \mu \mathrm{m}$ thick $\mu \mathrm{c}-\mathrm{Si}: \mathrm{H}$.

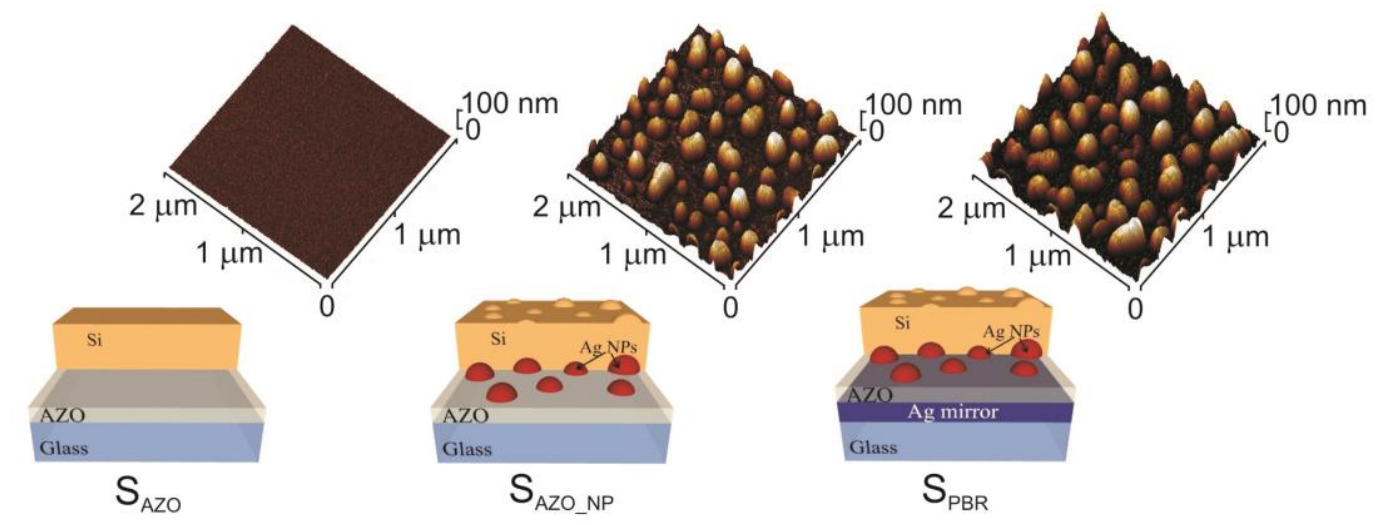

Fig. 9. Sketch and surface morphologies of the substrates used for the deposition of $0.9 \mu \mathrm{m}$ thick $\mu \mathrm{c}-\mathrm{Si}: \mathrm{H}: \quad \mathrm{S}_{\mathrm{AZO}}$ (AZO coated glass); $\mathrm{S}_{\mathrm{AZO} \_N P}$ (NPs on AZO); $\mathrm{S}_{\mathrm{PBR}}$ (NPs assembled in PBR structure). NPs were fabricated in the same deposition process from $12 \mathrm{~nm}$ thick Ag precursor films annealed at $400{ }^{\circ} \mathrm{C}$ for $1 \mathrm{~h}$. The thickness of all AZO films is $50 \mathrm{~nm}$.

As reported in section 3.1, the NPs' morphologies slightly change for the two different substrates. The AFM analyses reveal that the NPs have approximately hemispherical shape when formed on glass and tend to flatten out on AZO with maximum heights close to $100 \mathrm{~nm}$ in both cases. From the optical characterization (not shown here), the reference samples without NPs show negligible $R_{\text {Diff }}$ which increases in the presence of NPs. A substantially enhancement is observed when the NPs are coupled with a flat back reflector (PBR structure), due to the fact that the mirror not only reflects the transmitted diffuse light from the NPs but originates also a constructive nearfield interaction $[33,35]$.

The important issue for plasmon-induced light trapping is to discern between the absorption originating in the solar cell absorber layer (useful absorption) and in the metallic NPs (parasitic absorption), which are inseparable with standard transmission-reflection spectroscopy. Therefore, we developed a method consisting in a combination of photothermal deflection spectroscopy (PDS) and Fourier-transform photocurrent spectroscopy (FTPS) to independently quantify both absorption 
components within the sample (detailed description of the method can be found elsewhere [16,36]). The PDS signal accounts for all the light absorption processes that result in the generation of heat; thus for the investigated sample, PDS signal is a measure of the total absorption in the entire structure. On the other hand, the FTPS signal accounts only for the absorption processes that result in the generation of photocarries, thus being a measure of the useful absorption occurring in the $\mu \mathrm{c}$ $\mathrm{Si}: \mathrm{H}$ layer. As such, the difference between these two measurements determines the total parasitic losses.

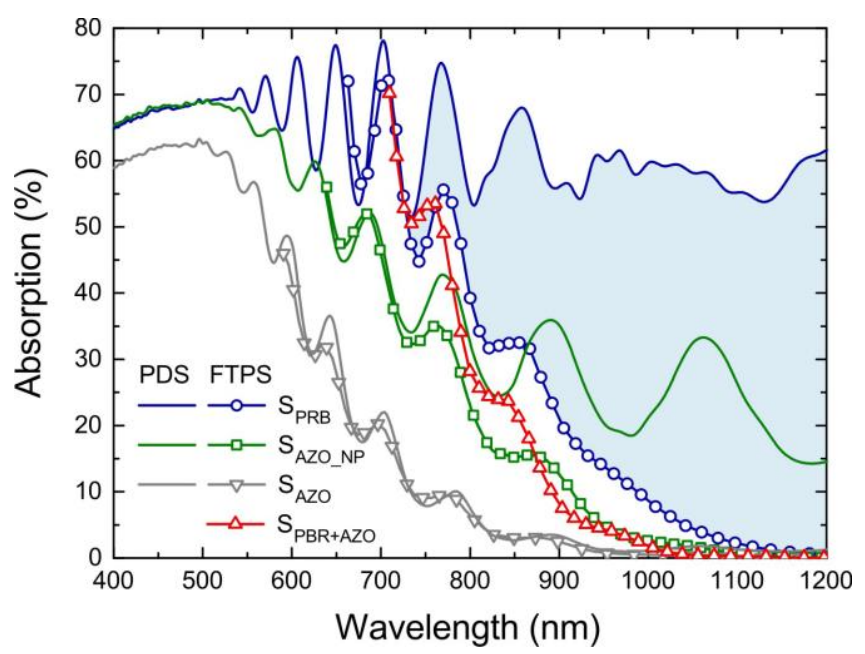

Fig. 10. Total (PDS) and useful (FTPS) absorption spectra of $0.9 \mu \mathrm{m}$ thick $\mu \mathrm{c}-\mathrm{Si}: \mathrm{H}$ deposited on samples $\mathrm{S}_{\mathrm{AZO}}, \mathrm{S}_{\mathrm{AZO} \_\mathrm{NP}}$, and $\mathrm{S}_{\mathrm{PBR}}$. The FTPS absorption for sample $S_{\mathrm{PBR}}$ with additional $50 \mathrm{~nm}$ thick AZO layer on top, sample $S_{\mathrm{PBR}+\mathrm{AZO}}$, is shown for comparison. The marked area (light blue) represents the parasitic absorption for sample $S_{\mathrm{PBR}}$.

Figure 10 depicts the useful (FTPS) and total (PDS) absorption spectra of the $0.9 \mu \mathrm{m}$ thick $\mu \mathrm{c}$ $\mathrm{Si}: H$ deposited on samples $\mathrm{S}_{\mathrm{AZO}}, \mathrm{S}_{\mathrm{AZO} \_N P}$, and $\mathrm{S}_{\mathrm{PBR}}$ shown schematically in Fig. 9 . In the reference $\mathrm{S}_{\mathrm{AZO}}$ sample, both PDS and FTPS signals overlap, indicating that practically all absorption occurs in the semiconductor and almost none in the AZO-coated glass substrate. In the presence of NPs (sample $\mathrm{S}_{\mathrm{AZO} \_\mathrm{NP}}$ ) a significant enhancement of the useful absorption is observed in the entire investigated $400-1200 \mathrm{~nm}$ wavelength range. The useful absorption for both samples containing NPs reach the same values below $500 \mathrm{~nm}$. However sample $S_{P B R}$ presents significantly higher useful absorption in the $500-1200 \mathrm{~nm}$ range, which is accompanied with significantly higher optical losses (parasitic absorption marked with light blue color in Fig. 10). The parasitic losses for both samples start to play a role only for wavelengths above $730 \mathrm{~nm}$, which are already poorly absorbed in a reference flat Si film, and increase significantly towards the bandgap of $\mu \mathrm{c}-\mathrm{Si}: \mathrm{H}$.

The enhancement at wavelengths below $500 \mathrm{~nm}$ can only be attributed to the antireflection action of the $\mu \mathrm{c}-\mathrm{Si}: \mathrm{H}$ corrugated surface resulting from its conformal deposition on the NPs, as at short wavelengths all photos are absorbed in the first pass through the cell with no interaction with NPs. On the other hand, the total parasitic absorption above $730 \mathrm{~nm}$ arises from multiple interactions between the light trapped in the silicon slab and the NPs [32]. As the number of such interactions for weakly absorbed near-infrared light increases substantially with decreasing absorption coefficient, the parasitic losses rapidly increase with illumination wavelength. However, it should be noted that the lambertian limit of absorption of $\mu \mathrm{c}-\mathrm{Si}: \mathrm{H}$ is substantially lower that total absorption measured 
from PDS signal. As such, only a part of parasitic absorption, being the difference between lambertian limit and useful absorption, can be considered as factual losses.

As already discussed in section 3.1, the scattering properties of particles are strongly dependent on the dielectric function of the embedding medium. Thus, the FTPS signal of sample similar to $S_{P B R}$, but with an additional $50 \mathrm{~nm}$ thick AZO layer separating NPs and silicon, was also acquired and reported on Fig. 10 - sample SPBR+Azo. A significant blue-shift of the absorption edge, and thus a clearly lower enhancement of useful absorption in the NIR region, is observed (the PDS signal of sample $S_{P B R+A Z O}$ - not shown here for the sake of clarity- exhibits similar values as sample $S_{P B R}$ ). This effect can be attributed to a lower light coupling efficiency $[13,24,37]$. Such top spacer layer in solar cells is required to act as a barrier for the diffusion of metal atoms into the silicon, thus preventing the deterioration of the electrical properties of the doped layer and consequent degradation of the cell junction. This suggests that the separation should be kept as thin as possible, to ensure high enhancement of useful absorption. Since the antireflection action provided by the surface texture is expected to contribute equally to light trapping in all samples containing NPs, and since the plasmonic scattering increases significantly in presence of the flat back mirror, it can be concluded that the enhancements of sample $\mathrm{S}_{\mathrm{PBR}}$ over $\mathrm{S}_{\mathrm{AZO} \text { NNP }}$ are dominated by plasmonic light trapping effects. Furthermore, a significant enhancement of $90 \%$ of the total useful absorption is measured on the $\mu-\mathrm{Si}: \mathrm{H}$ film deposited on $\mathrm{S}_{\mathrm{PBR}}$ with respect to the reference $\mathrm{S}_{\mathrm{AZO}}$ sample. The enhancement is attributed to both random texture of the front surface and plasmonic scattering from the rear.

\subsection{Plasmon-enhanced solar cells}

Finally, complete thin film photovoltaic devices were fabricated to investigate the benefits of plasmonic light trapping with our best-performing PBR. Such PBR, with NPs formed from a $12 \mathrm{~nm}$ thick $\mathrm{Ag}$ film annealed at $400{ }^{\circ} \mathrm{C}$ for $4 \mathrm{~h}$, was selected as substrate for the fabrication of n-i-p a-Si:H solar cells, schematically depicted in Fig. 11(a). A cross-section SEM (viewed at $20^{\circ}$ angle) of the fabricated device (Fig. 11(b)) revels NPs at the rear and a dome-shaped surface texture at the front resulting from the conformal growth of a-Si:H on top of the NPs. Reference cells i.e. without NPs were fabricated in the same process. 

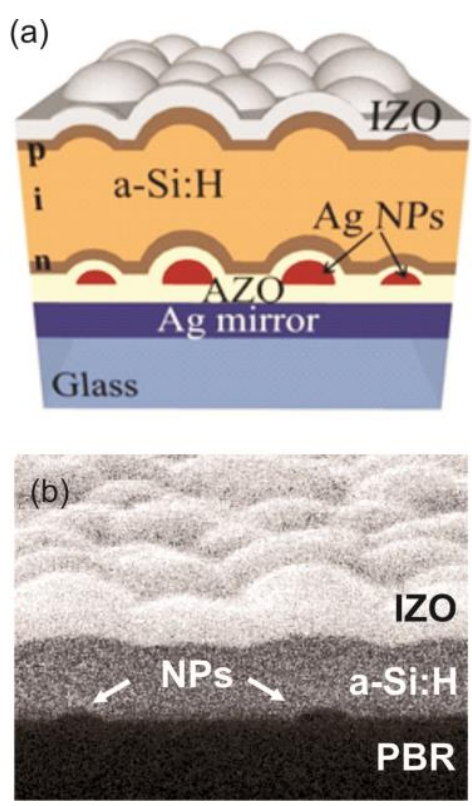

Fig. 11. Structure of a-Si:H n-i-p solar cell with plasmonic back reflector (PBR) shown (a) schematically and (b) in SEM cross section at a tilt angle of $20^{\circ}$. The SEM reveals NPs and the surface texture of the device fabricated on a PBR with NPs formed from a $12 \mathrm{~nm}$ thick Ag film annealed and $400{ }^{\circ} \mathrm{C}$ for $4 \mathrm{~h}$.

The EQE characteristics of the cells fabricated on the PBR and on a flat BR reference are shown in Fig. 12. PBRs provide a superior cell performance relative to the reference sample, over the entire measured range. In the UV-Vis range (for wavelengths below $570 \mathrm{~nm}$ ), the EQE enhancement can only be caused by the front texture of the solar cells, as in this spectral region all the incident light is absorbed in the Si layers during the first pass without interacting with the NPs. The light coupling and the antireflection properties provided by the dome-shaped texture are more effective than those given by the reference flat IZO layer [3].

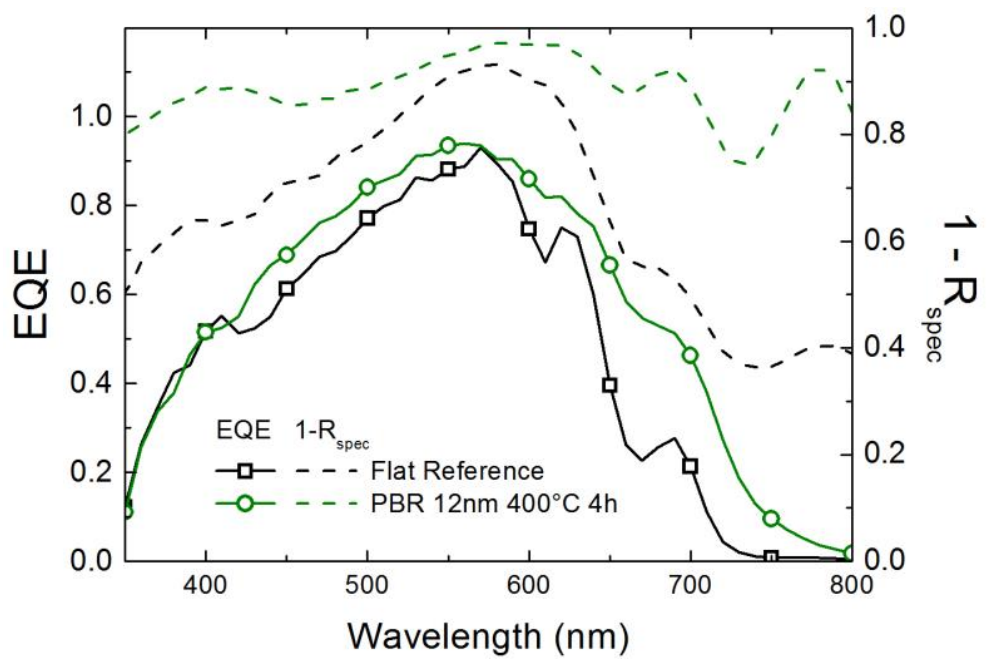

Fig. 12. EQE and 1-R $\mathrm{R}_{\mathrm{Spc}}$ curves of solar cells fabricated on PBRs with NPs formed from $12 \mathrm{~nm}$ thick Ag films annealed and $400{ }^{\circ} \mathrm{C}$ for $4 \mathrm{~h}$ in comparison with a reference cell with a flat back reflector.

An important insight on the light trapping effects is provided by the cell's reflection $(R)$, which 
indicates the absorption (1-R) in the device. The specular reflection at normal incidence $\left(\mathrm{R}_{\mathrm{Spec}}\right)$ has been plotted together with EQE curves in Fig. 12. A reasonably good spectral correlation between 1$\mathrm{R}_{\text {Spec }}$ and EQE is shown, illustrating the antireflection properties of the cells' surface texture. However, as the diffuse component of the reflection is not measured, the $1-\mathrm{R}_{\text {Spec }}$ curves give an overestimation of the total absorption in the cells, which might be significant in the red-NIR range of low absorption in a-Si:H. For wavelengths above $570 \mathrm{~nm}$ the EQE enhancement can be attributed to both the front surface texture and the plasmon-assisted scattering from the PBR. Although, the influence of the two mechanisms cannot be measured separately, computational studies indicate that moderate surface roughness observed in our experiments primarily influences the absorption in $\mathrm{Si}$ films for wavelengths below $500 \mathrm{~nm}$ [38]. On the other hand, Ag NP provide pronounced absorption enhancement at longer wavelengths $[13,15]$. Therefore, the main light trapping effect leading to the observed EQE enhancements in the red-NIR region is attributed to plasmon-assisted light scattering.

Lastly, we achieved a significant total photocurrent $\left(J_{s c}\right)$ enhancement of $22.3 \%$ for our best performing PBR relative to the reference flat device. Furthermore, the cell exhibits remarkably high values of $J_{s c}=15.75 \mathrm{~mA} / \mathrm{cm}^{2}$ and $V_{o c}=0.854 \mathrm{~V}$, which are among the highest reported so far in the literature for plasmon-enhanced a-Si:H solar cells with self-assembled NPs [27].

\section{Conclusion}

We review systematic studies of the structural and optical properties of self-assembled silver nanostructures, according to the fabrication parameters of the SSD process, on three consecutive stages of integration: NPs fabricated on glass substrates, NPs embedded in AZO, and NPs assembled in a PBR structure. These revealed that elevated annealing temperatures of $\sim 400^{\circ} \mathrm{C}$ and annealing time above $1 \mathrm{~h}$ are essential to obtain regularly shaped NPs with sizes between 100 and $200 \mathrm{~nm}$ in order to maximize plasmonic scattering and minimize parasitic absorption, which essential for application in photovoltaics.

An unprecedented procedure, consisting in a combination of opto-electronic spectroscopic techniques, namely PDS and FTPS, allowed the quantification of useful and parasitic absorption in $0.9 \mu \mathrm{m}$ thick $\mu \mathrm{c}-\mathrm{Si}: \mathrm{H}$ deposited on PBRs. This demonstrated that the optical losses related to plasmonic light trapping for such structure are insignificant in the wavelength range below $730 \mathrm{~nm}$, beyond which they increase rapidly with increasing illumination wavelength.

Optimized PBRs containing NPs formed from a $12 \mathrm{~nm}$ thick $\mathrm{Ag}$ film annealed at $400^{\circ} \mathrm{C}$ for $4 \mathrm{~h}$ allowed for a pronounced broadband photocurrent enhancement of $22.3 \%$ in a-Si:H solar cells, with remarkably high values of $\mathrm{Jsc}=15.75 \mathrm{~mA} / \mathrm{cm} 2$ and $\mathrm{Voc}=0.854 \mathrm{~V}$ achieved in comparison to those previously reported in the literature for the same type of devices. These results indicate that plasmonic light-trapping is a valid solution for implementation in the thin film PV.

\section{ACKNOWLEDGEMENTS}

This work was funded by the EU FP7 Marie Curie Action FP7-PEOPLE-2010-ITN through the PROPHET project (Grant No. 264687) and the bilateral CNR/AVCR project "Photoresponse of nanostructures for advanced photovoltaic applications". 
S.M. acknowledges funding from European Union's Horizon 2020 research and innovation programme under the Marie Skłodowska-Curie grant agreement No. 665778 through the "POLONEZ 1" funding scheme of National Science Centre, Poland (Fellowship no. 2015/19/P/ST5/03808).

M.J.M. acknowledges funding from FCT through the grant SFRH/BPD/115566/2016, FEDER funds, through the COMPETE 2020 Program, and national funds, through the FCT, under the projects POCI-01-0145-FEDER-007688 (Reference UID/CTM/50025) and ALTALUZ (Reference PTDC/CTM-ENE/5125/2014).

\section{$\underline{\text { References }}$}

[1] P. Spinelli, M.A. Verschuuren, A. Polman, Broadband omnidirectional antireflection coating based on subwavelength surface Mie resonators, Nat. Commun. 3 (2012) 692. http://dx.doi.org/10.1038/ncomms1691.

[2] E.R. Martins, J. Li, Y. Liu, V. Depauw, Z. Chen, J. Zhou, T.F. Krauss, Deterministic quasirandom nanostructures for photon control, Nat. Commun. 4 (2013) 2665. http://dx.doi.org/10.1038/ncomms3665.

[3] J. Zhu, C.-M. Hsu, Z. Yu, S. Fan, Y. Cui, Nanodome Solar Cells with Efficient Light Management and Self-Cleaning, Nano Lett. 10 (2010) 1979-1984. doi:10.1021/n19034237.

[4] M.J. Mendes, A. Araújo, A. Vicente, H. Águas, I. Ferreira, E. Fortunato, R. Martins, Design of optimized wave-optical spheroidal nanostructures for photonic-enhanced solar cells, Nano Energy. 26 (2016) 286-296. doi:https://doi.org/10.1016/j.nanoen.2016.05.038.

[5] C. Battaglia, C.-M. Hsu, K. Söderström, J. Escarré, F.-J. Haug, M. Charrière, M. Boccard, M. Despeisse, D.T.L. Alexander, M. Cantoni, Y. Cui, C. Ballif, Light Trapping in Solar Cells: Can Periodic Beat Random?, ACS Nano. 6 (2012) 2790-2797. doi:10.1021/nn300287j.

[6] H. a Atwater, A. Polman, Plasmonics for improved photovoltaic devices., Nat. Mater. 9 (2010) 205-13. doi:10.1038/nmat2629.

[7] Y.H. Jang, Y.J. Jang, S. Kim, L.N. Quan, K. Chung, D.H. Kim, Plasmonic Solar Cells: From Rational Design to Mechanism Overview, Chem. Rev. 116 (2016) 14982-15034. doi:10.1021/acs.chemrev.6b00302.

[8] V.E. Ferry, M.A. Verschuuren, M.C. van Lare, R.E.I. Schropp, H.A. Atwater, A. Polman, Optimized Spatial Correlations for Broadband Light Trapping Nanopatterns in High Efficiency Ultrathin Film a-Si:H Solar Cells, Nano Lett. 11 (2011) 4239-4245. doi:10.1021/nl202226r.

[9] H.R. Stuart, D.G. Hall, Island size effects in nanoparticle-enhanced photodetectors, Appl. Phys. Lett. 73 (1998) 3815-3817. doi:10.1063/1.122903.

[10] D. Derkacs, S.H. Lim, P. Matheu, W. Mar, E.T. Yu, Improved performance of amorphous silicon solar cells via scattering from surface plasmon polaritons in nearby metallic nanoparticles, Appl. Phys. Lett. 89 (2006) 93103. doi:10.1063/1.2336629.

[11] S. Pillai, K.R. Catchpole, T. Trupke, M. a. Green, Surface plasmon enhanced silicon solar cells, J. Appl. Phys. 101 (2007) 93105. doi:10.1063/1.2734885.

[12] A.J. Morfa, K.L. Rowlen, T.H. Reilly, M.J. Romero, J. van de Lagemaat, Plasmon-enhanced solar energy conversion in organic bulk heterojunction photovoltaics, Appl. Phys. Lett. 92 (2008) 13504. doi:10.1063/1.2823578.

[13] K.R. Catchpole, A. Polman, Design principles for particle plasmon enhanced solar cells, 191113 (2008) 1-4. doi:10.1063/1.3021072.

[14] K.R. Catchpole, A. Polman, Plasmonic solar cells., Opt. Express. 16 (2008) 21793-800. 
http://www.ncbi.nlm.nih.gov/pubmed/19104612.

[15] F.J. Beck, S. Mokkapati, K.R. Catchpole, Light trapping with plasmonic particles: beyond the dipole model., Opt. Express. 19 (2011) 25230-41.

[16] S. Morawiec, J. Holovský, M.J. Mendes, M. Müller, K. Ganzerová, A. Vetushka, M. Ledinský, F. Priolo, A. Fejfar, I. Crupi, Experimental quantification of useful and parasitic absorption of light in plasmon-enhanced thin silicon films for solar cells application, Sci. Rep. 6 (2016) 22481. doi:10.1038/srep22481.

[17] C.E.R. Disney, S. Pillai, M.A. Green, The Impact of parasitic loss on solar cells with plasmonic nano-textured rear reflectors, Sci. Rep. 7 (2017) 12826. doi:10.1038/s41598-01712896-1.

[18] C.S. Schuster, S. Morawiec, M.J. Mendes, M. Patrini, E.R. Martins, L. Lewis, I. Crupi, T.F. Krauss, Plasmonic and diffractive nanostructures for light trapping —an experimental comparison, Optica. 2 (2015) 194-200. doi:10.1364/OPTICA.2.000194.

[19] A. Gentile, F. Ruffino, G.M. Grimaldi, Complex-Morphology Metal-Based Nanostructures: Fabrication, Characterization, and Applications, Nanomater. . 6 (2016). doi:10.3390/nano6060110.

[20] C. V Thompson, Solid-State Dewetting of Thin Films, (2012). doi:10.1146/annurev-matsci070511-155048.

[21] S. Morawiec, M.J. Mendes, S. Mirabella, F. Simone, F. Priolo, I. Crupi, Self-assembled silver nanoparticles for plasmon-enhanced solar cell back reflectors: correlation between structural and optical properties, Nanotechnology. 24 (2013) 265601. doi:10.1088/09574484/24/26/265601.

[22] N.C. Lindquist, P. Nagpal, K.M. McPeak, D.J. Norris, S.-H. Oh, Engineering metallic nanostructures for plasmonics and nanophotonics, Reports Prog. Phys. 75 (2012) 36501. doi:10.1088/0034-4885/75/3/036501.

[23] D. Gaspar, A.C. Pimentel, M.J. Mendes, T. Mateus, B.P. Falcão, J.P. Leitão, J. Soares, A. Araújo, A. Vicente, S.A. Filonovich, H. Águas, R. Martins, I. Ferreira, Ag and Sn Nanoparticles to Enhance the Near-Infrared Absorbance of a-Si:H Thin Films, Plasmonics. 9 (2014) 1015-1023. doi:10.1007/s11468-014-9709-0.

[24] S. Pillai, F.J. Beck, K.R. Catchpole, Z. Ouyang, M. a. Green, The effect of dielectric spacer thickness on surface plasmon enhanced solar cells for front and rear side depositions, J. Appl. Phys. 109 (2011) 73105. doi:10.1063/1.3567299.

[25] S. Jain, V. Depauw, V.D. Miljkovic, A. Dmitriev, C. Trompoukis, I. Gordon, P. Van Dorpe, O. El Daif, Broadband absorption enhancement in ultra-thin crystalline Si solar cells by incorporating metallic and dielectric nanostructures in the back reflector, Prog. Photovoltaics Res. Appl. 23 (2015) 1144-1156. doi:10.1002/pip.2533.

[26] C. Eminian, F.-J. Haug, O. Cubero, X. Niquille, C. Ballif, Photocurrent enhancement in thin film amorphous silicon solar cells with silver nanoparticles, Prog. Photovoltaics Res. Appl. 19 (2011) 260-265. doi:10.1002/pip.1015.

[27] S. Morawiec, M.J. Mendes, S.A. Filonovich, T. Mateus, S. Mirabella, H. Águas, I. Ferreira, F. Simone, E. Fortunato, R. Martins, F. Priolo, I. Crupi, Broadband photocurrent enhancement in a-Si:H solar cells with plasmonic back reflectors, Opt. Express. 22 (2014) A1059-A1070. doi:10.1364/OE.22.0A1059.

[28] H. Tan, R. Santbergen, A.H.M. Smets, M. Zeman, Plasmonic Light Trapping in Thin-film Silicon Solar Cells with Improved Self-Assembled Silver Nanoparticles., Nano Lett. (2012). doi:10.1021/nl301521z.

[29] M.J. Mendes, S. Morawiec, T. Mateus, A. Lyubchyk, H. Águas, I. Ferreira, E. Fortunato, R. Martins, F. Priolo, I. Crupi, Broadband light trapping in thin film solar cells with selforganized plasmonic nano-colloids, Nanotechnology. 26 (2015) 135202. doi:10.1088/0957$4484 / 26 / 13 / 135202$. 
[30] T.L. Temple, D.M. Bagnall, Broadband scattering of the solar spectrum by spherical metal nanoparticles, Prog. Photovoltaics Res. Appl. 21 (2013) 600-611. doi:10.1002/pip.1237.

[31] A. Araújo, M.J. Mendes, T. Mateus, A. Vicente, D. Nunes, T. Calmeiro, E. Fortunato, H. Águas, R. Martins, Influence of the Substrate on the Morphology of Self-Assembled Silver Nanoparticles by Rapid Thermal Annealing, J. Phys. Chem. C. 120 (2016) 18235-18242. doi:10.1021/acs.jpcc.6b04283.

[32] A.M. Pennanen, J.J. Toppari, Direct optical measurement of light coupling into planar waveguide by plasmonic nanoparticles, Opt. Express. 21 (2013) A23-A35. doi:10.1364/OE.21.000A23.

[33] R. Santbergen, H. Tan, M. Zeman, A.H.M. Smets, Enhancing the driving field for plasmonic nanoparticles in thin-film solar cells, Opt. Express. 22 (2014) A1023-A1028. doi:10.1364/OE.22.0A1023.

[34] C. Pahud, O. Isabella, A. Naqavi, F.-J. Haug, M. Zeman, H.P. Herzig, C. Ballif, Plasmonic silicon solar cells: impact of material quality and geometry, Opt. Express. 21 (2013) A786A797. doi:10.1364/OE.21.00A786.

[35] M.J. Mendes, S. Morawiec, F. Simone, F. Priolo, I. Crupi, Colloidal plasmonic back reflectors for light trapping in solar cells, Nanoscale. 6 (2014) 4796-4805. doi:10.1039/C3NR06768H.

[36] J. Holovský, M. Schmid, M. Stuckelberger, M. Despeisse, C. Ballif, A. Poruba, M. Vaněček, Time evolution of surface defect states in hydrogenated amorphous silicon studied by photothermal and photocurrent spectroscopy and optical simulation, J. Non. Cryst. Solids. 358 (2012) 2035-2038. doi:https://doi.org/10.1016/j.jnoncrysol.2011.12.031.

[37] H. Tan, R. Santbergen, G. Yang, A.H.M. Smets, M. Zeman, Combined Optical and Electrical Design of Plasmonic Back Reflector for High-Efficiency Thin-Film Silicon Solar Cells, IEEE J. Photovoltaics. 3 (2013) 53-58. doi:10.1109/JPHOTOV.2012.2220528.

[38] P. Kowalczewski, M. Liscidini, L.C. Andreani, Light trapping in thin-film solar cells with randomly rough and hybrid textures, Opt. Express. 21 (2013) A808-A820. doi:10.1364/OE.21.00A808. 